\title{
Grade of Dysphonia: Correlation with Patient Self-Assessment Questionnaire and Acoustic Measures
}

\author{
FATMA EL-ZHRAA M. EL-METWALLY, M.Sc.; YOMNA H. ELFIKY, M.D. and RASHA M. SHOEIB, M.D. \\ The Department of ENT, Phoniatric Unit, Faculty of Medicine, Ain Shams University, Cairo, Egypt
}

\begin{abstract}
Background: The vocal assessment process should consider the multidimensionality involved in the demonstration of a voice disorder. Auditory perceptual assessment is the most commonly used clinical voice assessment method (gold standard) for evaluation of voice disorders. However, it has been heavily criticized because it is subjective and classifies severity of vocal disorders but does not address the impact of the vocal disorder has on quality of life which may go beyond the level of perceived voice change. So, it is possible that self-assessment instruments capture a different aspect of the vocal function that cannot be derived from auditoryperceptual or acoustic analysis.
\end{abstract}

Aim of Study: The aim of this work is to investigate the correlation between grade of dysphonia obtained by auditory perceptual assessment, acoustic measures and the degree of handicap a patient experiences (as measured by the Arabic $\mathrm{VHI}$ ) as a result of their voice disorder. study.

Study Design: This was a descriptive cross-sectional

Patients and Methods: 70 adult patients with voice complaints referred for voice evaluation in the Unite of Phoniatrics, Ain Shams University were included in this study aged 18 years-60 years and 35 normal adult subjects as a control group. Auditory perceptual assessment, acoustic analysis, and application of Arabic VHI questionnaire were done for all cases.

Results: A significant correlation was found between grade of dysphonia and functional subscale of the Arabic VHI Significant correlation was found between grade of dysphonia and amplitude perturbation quotient (APQ\%) and shimmer percent (Shim\%).

Significant correlation was found between Arabic VHI total score and average fundamental frequency (F0), significant correlation between functional subscale of the Arabic VHI and average fundamental frequency (F0) and jitter percent $(\mathrm{Jitt} \%)$ and near significant correlation between physical subscale of the Arabic VHI and average fundamental frequency.

Conclusion: Auditory perceptual assessment, acoustic analysis and patient's vocal self-assessment measure different aspects of the voice and are not interchangeable. These measures provide complementary rather than redundant information.

Correspondence to: Dr. Fatma El-Zhraa M. El-Metwally, E-Mail: Elzhraa28@gmail.com
Key Words: Dysphonia - Voice disorder - Patient selfassessment - Arabic VHI.

\section{Introduction}

AS the primary means of communication, voice plays an important role in daily life. Voice also conveys personal information such as social status, personal traits, and the emotional state of the speaker [1]. Voice is the acoustic outputs from the Larynx that are characterized by their dependence on vocal fold vibratory inputs. The quality of the voice is wholly dependent upon the vibratory characteristics of the laryngeal structure [2]. Disorders of voice present as deviations in voice quality which are considered a nature auditoryperceptual phenomenon. That is, a listener recognizes that a particular voice sounds unpleasant or seems inadequate relative to what is perceived to be "normal" by that listener [3]. Voice disorders can be classified into: Organic voice disorders "where there are detectable morphological changes in the vocal apparatus", non-organic voice disorders "where no visible structural or neurological pathology exists to explain the voice disturbance (the larynx is organically free)", Minimal Associated Pathological Lesions (MAPLs) "which is nonneoplastic, non-inflammatory, traumatic lesion of the vocal fold" and accompaniments of neuropsychiatric ailments "as an element of dysarthrophonia or personality and mood changes" [4]

The vocal assessment process should consider the multidimensionality involved in the demonstration of a voice disorder. The assessment should include perceptual assessment of vocal quality, aerodynamic measures, acoustic analysis, vocal self-assessment procedures and visual examination of the larynx. Each of these items has a specific relevance and provides particular information on voice disorder, whether in view of the clinician or 
the patient. Clinical decisions for treatment to be offered should use the integrated interpretation of these data, enabling the characterization of vocal behavior, identification of the possible etiology and triggering and maintaining factors, and description of the vocal adjustments used and the association between the vocal aspects and the impact caused on patient's communication [ $\boldsymbol{\Omega}$.

Auditory Perceptual Assessment (APA) is the most commonly used clinical voice assessment method and is often considered a gold standard for documentation of voice disorders [6]. However, APA classifies severity of vocal disorders but does not address the impact of the vocal disorder has on quality of life. The impact that the disorder has on quality of life may go beyond the level of perceived voice change [7]. Moreover, as a subjective method; these assessments may lead to different results depending on experience of the practitioner involved. Therefore, it became very important to search for an objective assessment, in which the voices were analyzed by devices which are capable of measuring several acoustic parameters which have the advantage of describing the voice objectively rather than subjectively [8]

One of the main domains in health-related quality of life is voice disordered quality of life; health-related quality of life refers to patientperceived impact of disease and treatment on physical, psychological, and social functions [9]. Therefore, the impact that the disorder has on quality of life may go beyond the level of perceived voice change. In practical terms, two subjects with similar dysphonia may experience different impacts on their quality of life, depending on their vocal needs. So, self-perception of vocal changes, as in any other specific health issue, is a factor that is difficult to measure and highly relevant to the voice therapy intervention process [7].

Therefore, various quality of life questionnaires have been developed for populations with voice disorders such as the Voice Symptom Scale (VoiSS) [10], the Voice Related Quality of Life Measure (V-RQOL) [11], the Vocal Performance Questionnaire (VPQ) [12], and the Voice Handicap Index (VHI) [13] . Although all of these questionnaires were valuable but VHI was more accepted and has been used widely in evaluation of outcome of treatments at clinics and in research. In addition, the Agency of Healthcare Research and Quality in 2012 announced the VHI as a valid and reliable diagnostic instrument [14]. The VHI has been translated and adapted to Arabic version "Arabic voice handicap index", which was validated in 2010 [15]
Of the vocal assessment procedures, there is greater integration among the auditory perceptual assessment, acoustic analysis and the patient's selfassessment of his or her voice problem. Thus, this study investigated the correlation between grade of dysphonia obtained by auditory perceptual assessment, acoustic measures and the degree of handicap a patient experiences (as measured by the Arabic VHI) as a result of their voice disorder in patients with voice disorders apart from organic voice disorders.

\section{Subjects and Methods}

This study was carried out on 70 adult patients who are complaining of any symptoms of voice disorders (dysphonia, phonasthenia, dysodia, or aphonia) referred for voice evaluation in the Unite of Phoniatrics, Ain Shams University in the period from July 2017 till January 2018 and 35 normal adult subjects as a control group who were selected randomly from individuals who didn't have any voice complaints around the same ages of the cases group. Among cases group, the patients' age ranged from 21 to 59 years with a mean of $40.45 \pm 10.92$ years while in the control group the ages ranged from 20 to 58 years with a mean of $38.09 \pm 10.93$. As regard the gender, cases were 23 females $(32.86 \%)$ and 47 males $(67.14 \%)$ while control group included 18 females $(51.4 \%)$ and 17 males $(48.57 \%)$. More than half of cases $(68.57 \%)$ were non-professional voice users. Also, $82.86 \%$ of the control group were non-professional voice users. A convenience sample was used to select the cases upon the following inclusion and exclusion criteria.

\section{Inclusion criteria:}

Patients complaining of any symptoms of voice disorders (dysphonia, phonasthenia, dysodia, or aphonia).

\section{Exclusion criteria:}

- Patients with endoscopic diagnosis of organic voice disorders.

- Patients were previously submitted to vocal rehabilitation or laryngeal surgery.

- Professional voice users in arts and performance.

- Patients younger than 18 years and older than 60 years as subjects less than 18 years may not give a reliable attitude towards voice problems and subjects older than 60 years may have age related changes in the larynx. 


\section{Procedures and clinical tools:}

For assessment of the patient, the following selected assessment steps, extracted from the voice assessment protocol [4] that is structured and used at the Unit of Phoniatrics Ain Shams University was used: (1) Patient's interview and case history taking including personal data, complaint and analysis of symptoms and impact of complaint on the patient from his/her viewpoint; (2) Auditory Perceptual Assessment (APA) stressing on the overall grade of dysphonia. Quality of voice is described according to modified GRBAS scale as: Overall grade; (G), Strained; (S), Leaky (L), Breathy; (B) and Irregular; (I). All elements of assessment are given a value on a scale from $0-4$; (3) Visualization of the glottis using a rigid telescope or flexible nasofibroscope; (4) Voice recording in a sound treated room; and (5) Acoustic analysis which done for every subject in the study (cases and control groups) using a computerized multidimensional voice program (MDVP, Multi speech copyright $($ 2000-2011 kay PENTAX version 3.4.1) to obtain these measures: Fundamental frequency (F0), Jitter \%, Relative average perturbation (RAP \%), Shimmer \%, Amplitude perturbation quotient (APQ \%) and Noise-to-Harmonic Ratio (NHR).

All patients were given an Arabic-voice handicap index (Arabic-VHI) [15] before starting the assessment protocol. It is the Arabic translated form of VHI [13]. The Arabic VHI is made up of 30 statements. These items are equally distributed over three domains: Functional, physical, and emotional aspects of voice disorders. The participated cases responded to each statement by giving a score ( 0 , never; 1 , almost never; 2 , sometimes; 3 , almost always; 4, always); VHI total scores range from 0 to 120 . Generally, a total VHI score from 0 to 30 denotes mild degree of handicap. A score of 10 points or less is considered as being normal. A score from 31 to 60 denotes moderate degree of handicap, and a score from 61 to 120 denotes a significant and serious degree of handicap due to voice problems.

\section{Results}

There was non-significant difference between the cases and control groups as regard age, sex and occupation.

Among cases group, using auditory perceptual analysis: Grade 2 dysphonia was the most frequent represented grade $(28.57 \%)$ followed by grade 1 $(24.29 \%)$ then grade $0(21.43 \%)$ then grade 3
$(18.57 \%)$ while grade 4 was the least frequent (7.14\%) as shown in Fig. (1).

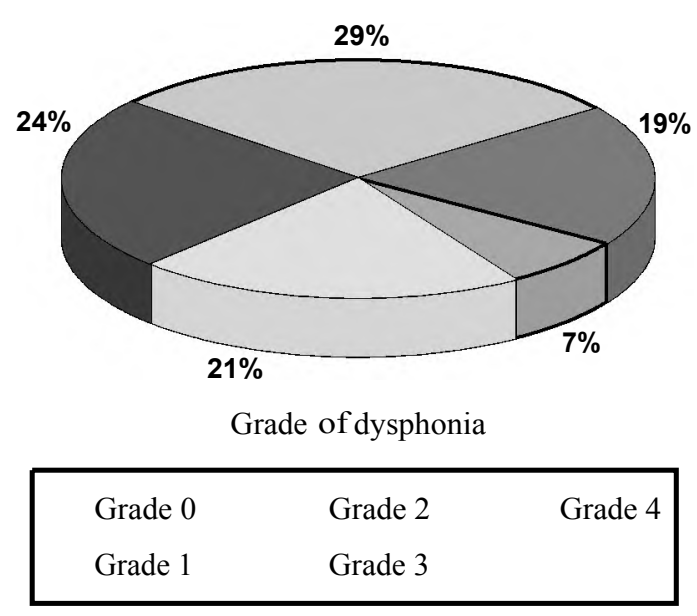

Fig. (1): Distribution of grade of dysphonia among the cases.

Cases were categorized into: 22 cases as vocal fold polyp; 15 cases as hyperfunctional dysphonia; 11 cases as phonasthenia; 7 cases as vocal fold nodules; 7 cases as vocal fold Reink's edema; 5 cases as vocal fold cyst; 1 case as contact granuloma and 1 case as polypoid degeneration; and 1 case as ventricular dysphonia Fig. (2).

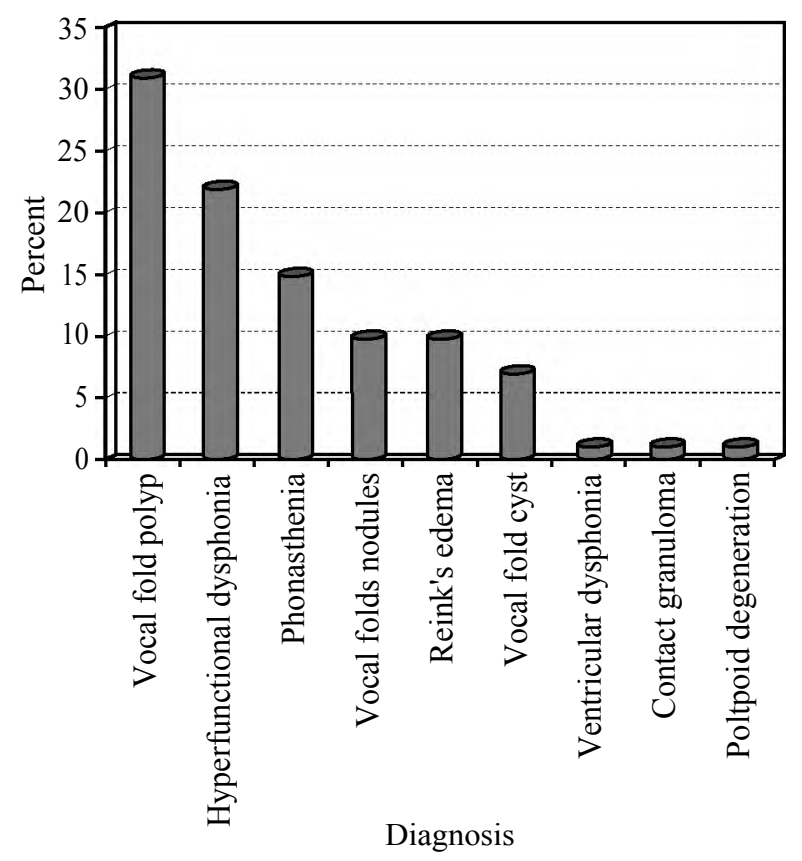

Fig. (2): Distribution of diagnosis among the cases.

Results of this study showed a highly significant difference between the cases and control groups as regard the studied acoustic parameters (F0, Jitt\%, RAP\%, Shim\%, APQ\% and NHR) (Table 1). 
Table (1): Comparison between cases and controls regarding acoustic parameters.

\begin{tabular}{|c|c|c|c|c|c|c|}
\hline & \multicolumn{2}{|c|}{ Case } & \multicolumn{2}{|c|}{ Control } & \multirow{2}{*}{$p^{* *}$} & \multirow{2}{*}{ Sig } \\
\hline & Mean $\pm \mathrm{SD}$ & Median (IQR*) & Mean \pm SD & Median (IQR*) & & \\
\hline F0 & $152.14 \pm 45.5$ & $\begin{array}{l}135.3 \\
(119.7-180.0)\end{array}$ & $191.59 \pm 49.9$ & $\begin{array}{l}189.2 \\
(145.16-242.4)\end{array}$ & 0.001 & HS \\
\hline Jitt $\%$ & $2.64 \pm 1.25$ & $\begin{array}{l}2.54 \\
(2.01-3.12)\end{array}$ & $0.77 \pm 0.28$ & $\begin{array}{l}0.75 \\
(0.58-0.9)\end{array}$ & 0.001 & HS \\
\hline RAP\% & $1.58 \pm 0.74$ & $\begin{array}{l}1.50 \\
(1.21-1.85)\end{array}$ & $0.43 \pm 0.16$ & $\begin{array}{l}0.38 \\
(0.34-0.5)\end{array}$ & 0.001 & HS \\
\hline Shim $\%$ & $5.47 \pm 3.33$ & $\begin{array}{l}4.83 \\
(3.03-6.89)\end{array}$ & $2.26 \pm 0.65$ & $\begin{array}{l}1.99 \\
(1.9-2.7)\end{array}$ & 0.001 & HS \\
\hline APQ\% & $3.75 \pm 2.1$ & $\begin{array}{l}3.33 \\
(2.12-4.85)\end{array}$ & $1.79 \pm 0.49$ & $\begin{array}{l}1.87 \\
(1.4-1.9)\end{array}$ & 0.001 & HS \\
\hline NHR & $0.16 \pm 0.06$ & $\begin{array}{l}0.15 \\
(0.12-0.17)\end{array}$ & $0.12 \pm 0.01$ & $\begin{array}{l}0.119 \\
(0.11-0.1)\end{array}$ & 0.001 & HS \\
\hline
\end{tabular}

Among cases group, VHI total score ranged from 3 to 112 with a mean of $49.93 \pm 27.27$. The functional subscale ranged from 0.0 to 36 with a mean of $13.75 \pm 10.32$. The physical subscale ranged from 1 to 40 with a mean of $21.97 \pm 9.73$. The emotional subscale ranged from 0 to 40 with a mean of $14.78 \pm 10.8$ as shown in (Table 2).

There was a significant difference between the females $(n=23)$ and males $(n=47)$ as regard the total score of VHI where females having higher scores $($ mean $=60.86 \pm 24.44)$ than males (mean= $44.81 \pm 27.25)$ as shown in (Table 3 ).

Correlations between grade of dysphonia and VHI total score and its three subscales among cases group $(\mathrm{n}=70)$ using Speaman's correlation test revealed a significant correlation $(\mathrm{Rs}=0.232)$ between grade of dysphonia and functional subscale of the VHI as shown in (Table 4).

Table (2): Description of VHI total score and its three subscales among cases group.

\begin{tabular}{lccccclc}
\hline & Mean & $\pm S D$ & Minim. & Maxim. & Median & \multicolumn{2}{c}{ IQR* } \\
\hline VHI total score & 49.93 & 27.27 & 3 & 112 & 44.00 & 30.00 & 73.00 \\
Functional & 13.75 & 10.32 & 0 & 36 & 14.00 & 6.00 & 21.00 \\
Physical & 21.97 & 9.73 & 1 & 40 & 19.00 & 15.00 & 30.00 \\
Emotional & 14.78 & 10.80 & 0 & 40 & 12.00 & 6.00 & 21.00 \\
\hline
\end{tabular}

*: Interquartile range.

Table (3): Comparison between males and females as regard VHI total score.

\begin{tabular}{|c|c|c|c|c|c|c|}
\hline & \multicolumn{4}{|c|}{ Sex } & \multirow{3}{*}{$p$} & \multirow{3}{*}{ Sig. } \\
\hline & \multicolumn{2}{|c|}{ Male } & \multicolumn{2}{|c|}{ Female } & & \\
\hline & Mean & $\pm \mathrm{SD}$ & Mean & $\pm \mathrm{SD}$ & & \\
\hline VHI total score & 44.81 & 27.25 & 60.86 & 24.44 & 0.022 & S \\
\hline \multicolumn{7}{|l|}{ *: Student $t$-test. } \\
\hline \multicolumn{7}{|c|}{$\begin{array}{l}\text { Table (4): Correlations between grade of dysphonia and VHI } \\
\text { total score and its three subscales among cases } \\
\text { group. }\end{array}$} \\
\hline
\end{tabular}

\begin{tabular}{lcccc}
\hline & $\begin{array}{c}\text { VHI total } \\
\text { score }\end{array}$ & $\begin{array}{c}\text { Functional } \\
\text { subscale }\end{array}$ & $\begin{array}{c}\text { Physical } \\
\text { subscale }\end{array}$ & $\begin{array}{c}\text { Emotional } \\
\text { subscale }\end{array}$ \\
\hline $\begin{array}{l}\text { Grade of } \\
\text { dysphonia: }\end{array}$ & & & & \\
Rs* & 0.195 & 0.232 & 0.167 & 0.168 \\
$p$ & 0.109 & 0.05 & 0.170 & 0.168 \\
Sig & NS & S & NS & NS \\
\hline *: Speaeman correlation coefficet. & \multicolumn{3}{c}{ Spearman's rho. }
\end{tabular}

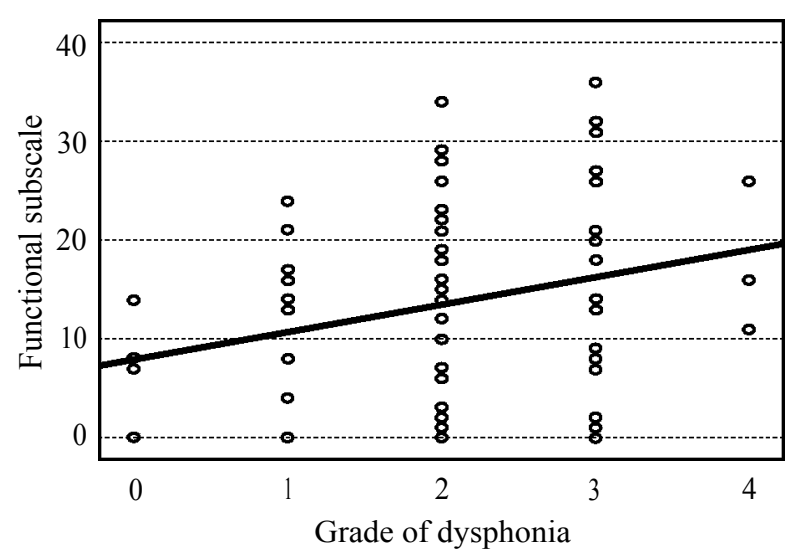

Fig. (3): Correlations between grade of dysphonia and functional subscale of VHI.

Speaman's correlation between grade of dysphonia and acoustic parameters revealed that there was a significant correlation between grade of dysphonia and amplitude perturbation quotient 
$(\mathrm{APQ})(\mathrm{Rs}=0.249)$ and near significant correlation between grade of dysphonia and shimmer percent $(\mathrm{Shim} \%)(\mathrm{Rs}=0.209)$ as shown in (Table 5).

Table (5): Correlations between grade of dysphonia and acoustic parameters.

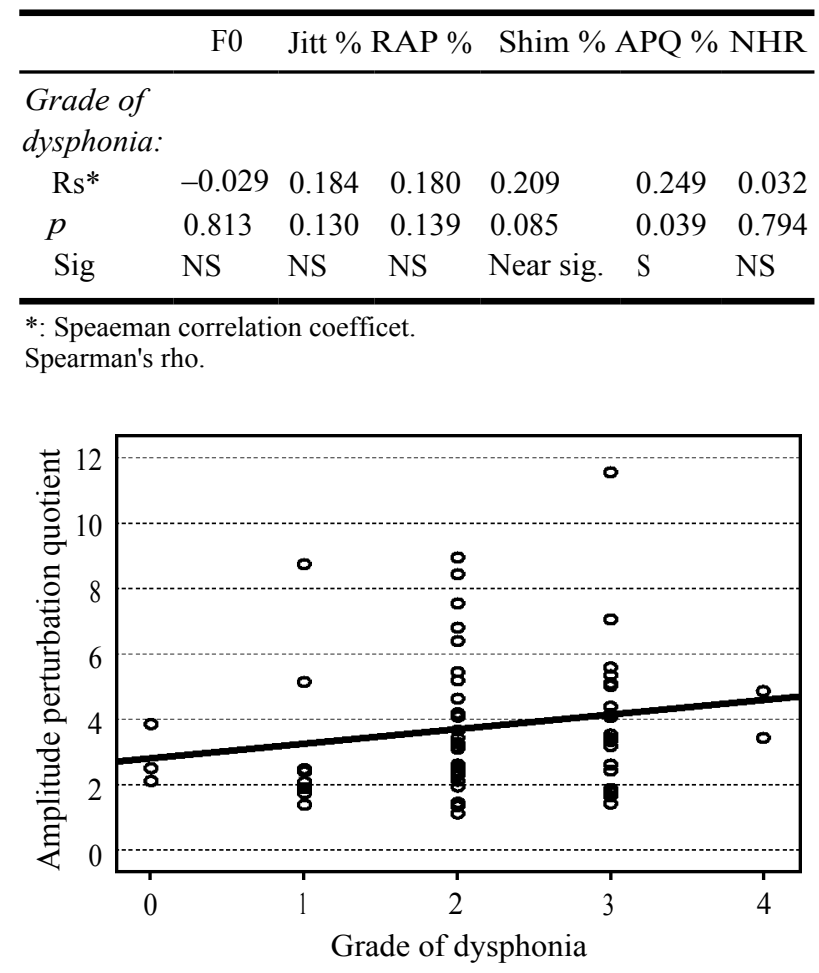

Fig. (4): Correlations between grade of dysphonia and APQ.

Using Spearman's correlation test: There was a significant correlation between VHI total score and average fundamental frequency $(\mathrm{F} 0)(\mathrm{Rs}=$ 0.240) (Table 6); significant correlation between functional subscale of the VHI and average fundamental frequency (F0) and jitter percent (Jitt\%) as $(\mathrm{Rs}=0.244),(\mathrm{Rs}=0.236)$ respectively $($ Table 7$)$ and near significant correlation between physical subscale of the VHI and average fundamental frequency $(\mathrm{F} 0)(\mathrm{Rs}=0.210)$ (Table 8$)$. But there was no correlation between emotional subscale of the VHI and any of the acoustic parameters as shown in (Table 9).

Table (6): Correlations between VHI total score and acoustic parameters among cases group.

\begin{tabular}{lllllll}
\hline \multicolumn{1}{c}{ F0 } & Jitt \% & RAP \% & Shim \% & APQ \% & NHR \\
\hline VHI total & & & & & & \\
score: & & & & & & \\
Rs* & $0.240(*)$ & 0.181 & 0.166 & 0.089 & 0.044 & 0.048 \\
$p$ & 0.047 & 0.136 & 0.173 & 0.466 & 0.718 & 0.694 \\
Sig & S & NS & NS & NS & NS & NS \\
\hline
\end{tabular}

*: Speaeman correlation coefficet.

Spearman's rho.
Table (7): Correlations between functional subscale score and acoustic parameters among cases group.

F0 Jitt \% RAP \% Shim \% APQ \% NHR

\begin{tabular}{lllllll}
\hline $\begin{array}{l}\text { Functional } \\
\text { subscale: }\end{array}$ & & & & & & \\
Rs* & 0.244 & 0.236 & 0.178 & 0.137 & 0.153 & 0.193 \\
$p$ & 0.043 & 0.05 & 0.144 & 0.260 & 0.209 & 0.112 \\
Sig & $\mathrm{S}$ & $\mathrm{S}$ & $\mathrm{NS}$ & $\mathrm{NS}$ & $\mathrm{NS}$ & $\mathrm{NS}$ \\
\hline
\end{tabular}

*: Speaeman correlation coefficet.

Spearman's rho.

Table (8): Correlations between physical subscale score and acoustic parameters among cases group.

\begin{tabular}{|c|c|c|c|c|c|c|}
\hline & F0 & Jitt \% & RAP \% & Shim \% & APQ \% & NHR \\
\hline \multicolumn{7}{|c|}{$\begin{array}{l}\text { Physical } \\
\text { subscale: }\end{array}$} \\
\hline Rs* & 0.210 & 0.166 & 0.154 & 0.021 & -0.018 & -0.006 \\
\hline$p$ & 0.083 & 0.174 & 0.207 & 0.861 & 0.881 & 0.962 \\
\hline Sig & Near si & . NS & NS & NS & NS & NS \\
\hline
\end{tabular}

Table (9): Correlations between emotional subscale score and acoustic parameters among cases group.

\begin{tabular}{|c|c|c|c|c|c|c|}
\hline \multirow[b]{2}{*}{$\begin{array}{l}\text { Emotiona } \\
\text { subscale: }\end{array}$} & \multirow[t]{2}{*}{ F0 } & \multicolumn{2}{|c|}{ Jitt \% RAP \% } & \multicolumn{2}{|c|}{ Shim \% APQ \% } & \multirow[t]{2}{*}{ NHR } \\
\hline & & & & & & \\
\hline $\mathrm{Rs}^{*}$ & 0.153 & 0.135 & 0.125 & 0.107 & 0.059 & 0.032 \\
\hline$p$ & 0.209 & 0.270 & 0.307 & 0.383 & 0.631 & 0.792 \\
\hline Sig & NS & NS & NS & NS & NS & NS \\
\hline
\end{tabular}

*: Speaeman correlation coefficet

Spearman's rho.

\section{Discussion}

The purpose of this study is to determine if grade of dysphonia obtained from auditory perceptual assessment and acoustic measures correlate with patient's vocal self-assessment using Arabic voice handicap index (Arabic VHI) in patients with voice disorders apart from organic voice disorders.

The assessment of dysphonia in patients with voice disorders remains a significant challenge. There is no single criterion standard measure for assessment of voice outcome. Although the 'ear' is an important instrument in analyzing voice quality and should always be considered during voice evaluation, objective measures such as acoustic and aerodynamic assessments offer supplemental unbiased documentation of voice change over time [16].

Among the different instruments that assess the impact of voice disorders on the quality of life, the Arabic VHI was chosen to be used in this study. The Arabic VHI is made up of 30 statements. These 
items are equally distributed over three domains: Functional, physical, and emotional aspects of voice disorders. Malki et al., [12] concluded that the Arabic VHI had strong internal consistency that was clearly demonstrated in both the study and the control groups and had excellent test-retest reliability for both the total VHI scores and the individual domain scores. In addition, the three domains of the Arabic VHI had also shown a strong internal consistency. Arabic VHI is rapidly administered and easily scored Voice Disorders Quality of Life (VDQOL) instrument that can be applied for all patients without training. It is worded in a manner that makes it simple and easily understood by patients and took only few minutes to complete.

In this study, higher mean physical subscale scores of the Arabic VHI were found in comparison to the functional and emotional domains, which coincides with previous reported studies $[15,17,18]$ Those investigators have previously suggested that because of the familiarity of subjects with physical symptoms of voice disorders (strain, roughness, etc.), they tend to identify those symptoms more easily.

Meanwhile, the association with emotional and functional symptoms (fear, etc.) is less of a direct association [19]. This was clearly demonstrated in our study as functional and emotional subscales scores of the VHI were similar to each other and lower than the physical subscale scores. These findings emphasize the physical aspects of the VHI being the most prominent self-perceived parameters of voice problems.

The biopsychosocial consequences related to voice disorders seem to be worse among women than men. This is apparent clearly in the higher score of VHI total score among female patients than male patients in this study. This was a common finding in Taguchi et al., [20] study who noted that women with dysphonia obtained significantly higher VHI scores than men. This finding is matching also with Niebudek-Bogusz et al., [21] who explained this by that women are possibly more concerned about their voice disorders as compared to males.

In this study, there is correlation between grade of dysphonia and functional subscale of the VHI. This is in agreement with the results of Ghandour and Kaddah [16] study where Auditory Perceptual Assessment (APA) was found to be predictive of the functional and physical domains of the Arabic paediatric VHI as represented by the significant correlation between these parameters.
Another study by Bauer et al., [22] who compared voice self-assessment with APA in patients with multiple Sclerosis found no significant correlation between overall VHI or its subscales and any of the GRBAS scale components for male participants. However, they found significant positive correlation between VHI and physical subscale of VHI with the GRBAS overall score among female participants. So, they concluded that the VHI is a good and effective tool to assess a patient's self-perception of the voice quality, but it may not reflect the severity of dysphonia as perceived by voice and speech professionals.

The voice analysis is becoming nowadays a very valuable technique for voice disorders diagnose. Patient's voice quality can be diagnosed by auditory perceptual analysis. However, these analyses may lead to different results depending on experience of the practitioner involved. Using subjective assessment technique alone leads to lack of consensus among professionals. Therefore, it became very important to search for an objective assessment, in which the voices were analysed by devices which are capable of measuring several acoustic parameters which have the advantage of describing the voice objectively rather than subjective perceptual analysis. With the existence of normative databases characterizing voice quality or using intelligent tools combining several parameters, it is intended to distinguish between normal and pathological voice or even identify or suggest the pathology [8]. This was clearly described in our study as there was highly significant difference between the cases and control groups as regard the studied acoustic parameters.

Voice analysis is performed with specific software tools. Widely used voice analysis programs include multi-dimensional voice Program (MDVP), doctor speech, praat and visi-pitch, which are used among others for finding the regulation of voice data and dysphonia. MDVP has been widely used in literature, as vocal characteristics' influences have been examined in many studies in patients with multiple voice disorders [23].

Minor disturbances in the frequency and the amplitude of the voice signal, called perturbations, are unavoidably present even when one tries to produce a perfectly steady sound. In patients with a voice problem, perturbation may become worse and result in a more severe deviation from the normal voicing pattern. Perceptually, this may be interpreted as dysphonia and described using labels like irregular, breathy and rough. Popular acoustic metrics to assess dysphonia are jitter and shimmer, 
denoting short-term (cycle-to-cycle) variability in fundamental frequency (F0) and amplitude, respectively [24]

This agree with the results of our study which showed correlation between grade of dysphonia and acoustic measures in the form of significant correlation between grade of dysphonia and amplitude perturbation quotient and near significant correlation between grade of dysphonia and shimmer percent. This is in the same context with Ghandour et al., [25] study in which dysphonia was found significantly correlated to the acoustic parameters (jitter, shimmer and NHR). Both jitter and shimmer have been described as objective measures of the biomechanical vibratory properties of the vocal folds, which are considered central to the determination of vocal quality. In measuring pitch and amplitude perturbation, it has been presumed that jitter and shimmer indicate different aspects of perceptual dysphonia [26]

The standard deviation of FO is a measure directly related to the neuromuscular condition and mucosal vibration regularity of the vocal folds [27] . In this study average fundamental frequency (F0) was correlated with VHI total score, functional subscale and physical subscale. This was a common finding in Tarazani et al., [28] study that showed correlation between FO and total VHI as well as functional, physical and emotional domains of VHI in patients with primary Muscle Tension Dysphonia (MTD). With regard to the correlation found between F0 and perceived voice-related disability, it seems that F0 is an important perceived acoustical quality of the dysphonic voice.

In this study, jitter percent was found to be correlated with functional subscale of the VHI only but in Tarazani et al., [28] study, jitter percent showed a very good correlation with VHI total score, functional subscale and the emotional subscale of VHI which seems that jitter is associated with different aspects of voice-perceived disability in patients with secondary MTD, because lesions in the vocal folds cause irregularity in vocal fold vibration and also increase quality disorders.

In Schindler et al., [29] study they categorized the patients with dysphonia according to the underlying etiology for evaluating the correlation between VHI and voice measurements. Patients were divided into four groups including functional dysphonia, unilateral vocal fold paralysis, structural dysphonia and nodules. The authors reported strong correlation between jitter and functional VHI domain in group 2, and physical VHI domain and jitter, shimmer and NHR in group 4. Therefore, they concluded that different acoustic parameters are associated with different aspects of voiceperceived disability. Furthermore, they concluded in the same study that acoustic measures and VHI proved to be independent when patients with voice disorders of different etiologies (functional dysphonia, unilateral vocal fold paralysis, nodules, cysts, polyps, and Reinke's edema) were analyzed together. However, when analyzed separately, there was a positive correlation between VHI and acoustic measurements.

Lopes et al., [5] studied correlation between the acoustic measurements and the VHI score and found that there was no correlation between those measures. Also, Kiagiadaki et al., [30] compared the acoustic measurements, as well as an auditoryperceptual analysis and videostroboscopic examination of the larynx using the VHI with the VoiSS before and after surgery to remove benign laryngeal lesions, and it was observed that there was no correlation between the VHI and other measures carried out in the pre-and postintervention situations.

Research by Gillespie et al., [31] analyzed the correlation between acoustic measurements and the VHI in pre-and postintervention situations. There was no correlation between these measurements in both situations. However, there was greater change in VHI than in acoustic measures in the postintervention situation.

Between voice handicap and acoustic measures, some studies $[32,33]$ indicate that there is a correlation. However, others $[\mathbf{3 4 , 3 5}$ ] suggest that acoustic measures are not among the factors that predict voice handicap in a patient. Awan et al., [33] concluded that although the self-evaluation and acoustic measurements can be sensitive to vocal disability, the linear relationship between these two approaches does not seem to be strong, especially when using the VHI as the self-assessment tool.

\section{Conclusion:}

Voice quality is perceptual in nature so, the perceptual characteristics of voice have greater intuitive meaning and shared reality among listeners than do many instrumental measures. Also, objective laboratory tests as acoustic analysis are needed to accurately and reliably characterize the severity of dysphonia and measure specific parameters of the voice. However, both perceptual analysis and acoustic analysis cannot assess the global impact of a voice disorder on patients' emotional, functional, and physical perceptions of health. Conse- 
quently, patient self-assessment voice disorder quality of life instrument as Arabic VHI is valuable, applicable and can be used along with other objective tools to assess the impact of ones' voice characteristics on his/her quality of life which may go beyond the level of perceived voice change.

\section{Recommendations:}

Our sample included patients with different voice disorders apart from the organic voice disorders and who had not undergone prior treatment, which probably covers a wide range of intensity of vocal deviation and justifies the inconsistency of correlation in this study. Thus, future studies with larger sample sizes and similar diagnoses are needed.

Further studies could be conducted using acoustic parameters other than the traditional used ones. Different results could be found on the correlation between acoustic parameters, perceptual assessment and self-assessment if other acoustic parameters were used.

\section{References}

1- ZHANG Z.: Mechanics of human voice production and control. J. Acoust. Soc. Am., 140 (4): 2614-35, 2016.

2- DANIEL A. and STANLEY A.B.: Clinical Analysis of Hoarseness in Children as Seen in Otorhinolaryngology Department of a Tertiary Health Institution in North-West, Nigeria. Open J. Pediatr., 6 (1): 17, 2016.

3- ZRAICK R.I., KEMPSTER G.B., CONNOR N.P., et al.: Establishing validity of the consensus auditory-perceptual evaluation of voice (CAPE-V). Am. J. Speech-Language Pathol., 20 (1): 14-22, 2011.

4- KOTBY M.N. and BARAKA M. AEEMYESSESA, N.R.: Introduction to Vocology. In: Clinical Vocology. Cairo Egypt Soc. Phoniatr. Logop., 1, 2016.

5- LOPES L.W., Da SILVA J.D., SIMÕES L.B., et al. Relationship between acoustic measurements and selfevaluation in patients with voice disorders. J. Voice, 31 (1): 119-e1, 2017.

6- OATES J.: Auditory-perceptual evaluation of disordered voice quality. Folia Phoniatr. Logop., 61 (1): 49-56, 2009.

7- SPINA A.L., MAUNSELL R., SANDALO K., GUSMÃO R. and CRESPO A.: Correla $\{c ̧\}\{\tilde{a}\}$ o da qualidade de vida e voz com atividade profissional. Braz. J. Otorhinolaryngol., 75 (2), 2009.

8- TEIXEIRA J.P. and FERNANDES P.O.: Acoustic analysis of vocal dysphonia. Procedia Comput. Sci., 64: 466-73, 2015.

9- DEHQAN A., YADEGARI F., ASGARI A., SCHERER R.C. and DABIRMOGHADAM P.: A qualitative exploration of voice oriented quality of life in Iranian patients: A cultural explanation. Glob. J. Heal. Sci., 9, 2017.

10-DEARY I.J., WILSON J.A., CARDING P.N., MacKENZIE K. and VOI S.S.: A patient-derived voice symptom scale. J. Psychosom. Res., 54 (5): 483-9, 2003.
11- HOGIKYAN N.D. and SETHURAMAN G.: Validation of an instrument to measure voice-related quality of life (V-RQOL). J. voice, 13 (4): 557-69, 1999.

12- CARDING P.N., HORSLEY I.A. and DOCHERTY G.J.: A study of the effectiveness of voice therapy in the treatment of 45 patients with nonorganic dysphonia. J. voice, 13 (1): 72-104, 1999.

13- JACOBSON B.H., JOHNSON A., GRYWALSKI C., et al.: The voice handicap index (VHI): Development and validation. Am. J. Speech-Language Pathol., 6 (3): 6670, 1997.

14- SEIFPANAHI S., JALAIE S., NIKOO M.R. and SOBHANI-RAD D.: Translated versions of Voice Handicap Index (VHI)-30 across languages: A systematic review. Iran J. Public Health, 44 (4): 458, 2015.

15- MALKI K.H., MESALLAM T.A., FARAHAT M., BUKHARI M. and MURRY T.: Validation and cultural modification of Arabic voice handicap index. Eur. Arch. Oto-Rhino-Laryngology, 267 (11): 1743-51, 2010.

16- GHANDOUR H.H. and KADDAH F.A.A., Others: Correlation between the Arabic pediatric voice handicap index and both the auditory perceptual assessment and acoustic analysis of voice in patients with hyperfunctional childhood dysphonia. Egypt J. Otolaryngol., 29 (2): 124 2013.

17- LAM P.K.Y., CHAN K.M., HO W.K., KWONG E., YIU E.M. and WEI W.I.: Cross-cultural Adaptation and Validation of the Chinese Voice Handicap Index-10. Laryngoscope, 116 (7): 1192-8, 2006.

18- HAKKESTEEGT M.M., WIERINGA M.H., GERRITSMA E.J. and FEENSTRA L.: Reproducibility of the Dutch version of the Voice Handicap Index. Folia Phoniatr. Logop., 58 (2): 132-8, 2006.

19- HELIDONI M.E., MURRY T., MOSCHANDREAS J., LIONIS C., PRINTZA A. and VELEGRAKIS G.A.: Crosscultural adaptation and validation of the voice handicap index into Greek. J. Voice, 24 (2): 221-7, 2010.

20- TAGUCHI A., MISE K., NISHIKUBO K., HYODO M and SHIROMOTO O.: Japanese version of voice handicap index for subjective evaluation of voice disorder. J. Voice, 26 (5): 668-e15, 2012.

21- NIEBUDEK-BOGUSZ E., KUZANSKA A., WOZNICKA E. and SLIWINSKA-KOWALSKA M.: Assessment of the voice handicap index as a screening tool in dysphonic patients. Folia. Phoniatr. Logop., 63 (5): 269-72, 2011.

22- BAUER V., ALERIC Z. and JANCIC E.: Comparing Voice Self-Assessment with Auditory Perceptual Analysis in Patients with Multiple Sclerosis. Int. Arch. Otorhinolaryngol., 19 (2): 100-5, 2015.

23- GEREDAKIS A., KARALA M., ZIAVRA N. and TOKI E.: Preliminary Measurements of Voice Parameters using Multi Dimensional Voice Program. signal. 23: 31.

24- MARYN Y., CORTHALS P., De BODT M., VAN CAUWENBERGE P. and DELIYSKI D.: Perturbation measures of voice: A comparative study between Multi-Dimensional Voice Program and Praat. Folia Phoniatr. Logop., 61 (4): 217-26, 2009.

25- GHANDOUR H., NASSAR J. and SHOEIB R.: Correlation between voice handicap index scores and both acoustic 
measures and grade of dysphonia in non-organic voice disorders. Sci. J. Az. Med. Fac., 28: 559-68, 2007.

26- BROCKMANN-BAUSER M. and DRINNAN M.J.: Routine acoustic voice analysis: Time to think again? Curr. Opin. Otolaryngol. Head Neck Surg., 19 (3): 165-70, 2011.

27- JOTZ G.P., CERVANTES O., SETTANI F.A.P. and ANGELIS E.C. De.: Acoustic measures for the detection of hoarseness in children. Int. Arch. Otorhinolaryngol., 10 (1): 14-20, 2006.

28- TARAZANI M., KHODDAMI S.M., JALAIE S., MOGHADAM S.T. and AKBARI M.: The correlation between voice handicap index and specific acoustic measures in patients with muscle tension dysphonia. Thrita, 2 (3): 24$8,2013$.

29- SCHINDLER A., MOZZANICA F., VEDRODY M., MARUZZI P. and OTTAVIANI F.: Correlation between the Voice Handicap Index and voice measurements in four groups of patients with dysphonia. Otolaryngol. Neck Surg., 141 (6): 762-9, 2009.

30- KIAGIADAKI D.E., CHIMONA T.S., CHLOUVERAKIS G.I., et al.: Evaluating the outcome of phonosurgery:
Comparing the role of VHI and VoiSS questionnaires in the Greek language. J. Voice, 26 (3): 372-7, 2012.

31- GILLESPIE A.I., GOODING W., ROSEN C. and GARTNER-SCHMIDT J.: Correlation of VHI-10 to voice laboratory measurements across five common voice disorders. J. Voice, 28 (4): 440-8, 2014.

32- GONZÁLEZ B.S., BATALLA F.N., SANTOS P.C. and NIETO C.S.: $\{$ Í $\}$ ndice de incapacidad vocal: Factores predictivos. Acta Otorrinolaringol \{ó $\}$ gica Espa $\{\tilde{n}\}$ ola. 57 (2): 101-8, 2006.

33- AWAN S.N., ROY N. and COHEN S.M.: Exploring the relationship between spectral and cepstral measures of voice and the Voice Handicap Index (VHI). J. Voice, 28 (4): 430-9, 2014.

34- BEHRMAN A., SULICA L. and HE T.: Factors predicting patient perception of dysphonia caused by benign vocal fold lesions. Laryngoscope, 114 (10): 1693-700, 2004.

35- De CEBAllos A.G. Da C., CARVALHO F.M., De Araújo T.M. and Dos REIS E.J.F.B.: Diagnostic validity of Voice Handicap Index-10 (VHI-10) compared with perceptive-auditory and acoustic speech pathology evaluations of the voice. J. Voice, 24 (6): 715-8, 2010.

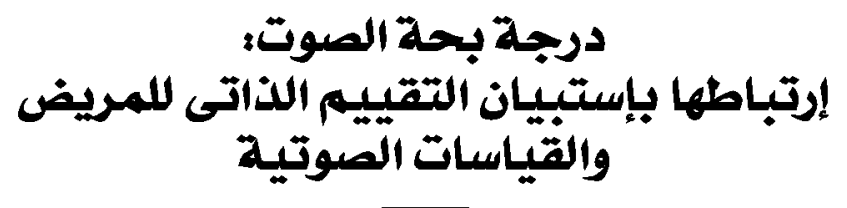

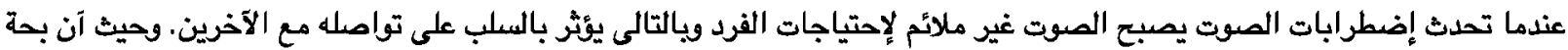

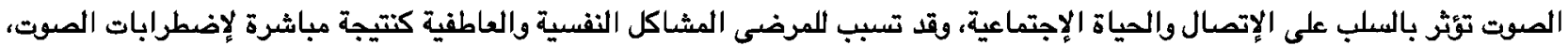
وبالتالى فإنها تؤثر سلبيا على جودة حياة المريض.

ينبفى آن تككن عملية تقييم الصوت معبرة عن الديناميكية المتمثة فى إضطرابات الصوت. حيث يجب آن يشمل التقييم فحصا بصريا

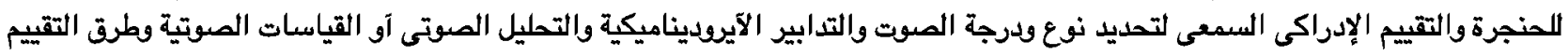

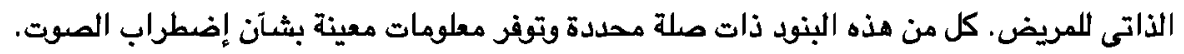

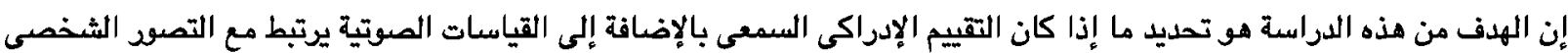

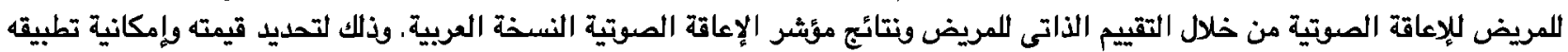
في عيادة آمراض التخاطب.

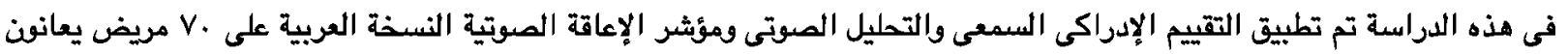

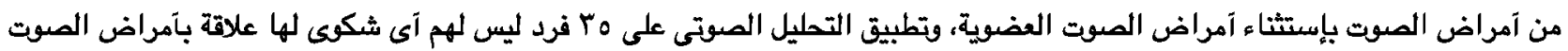

